\title{
A Judicialização da Saúde: Aspectos Jurídicos e Éticos da Lei 13.269/2016 Sobre o Uso da Fosfoetalonamina Sintética para Pacientes Diagnosticados com Neoplasia Maligna
}

THE JUDICIALIZATION OF HEALTH: LEGAL AND ETHICAL ASPECTS OF LAW 13.269/2016 ON THE USE OF SYNTHETIC PHOSPHOETHANOLAMINE FOR PATIENTS DIAGNOSED WITH MALIGNA NEOPLASIA

Cássia Cristina Lemes DE PAULA ${ }^{1}$ Danilo Henrique NUNES ${ }^{2}$

${ }^{1}$ Centro Universitário da Fundação Educacional de Barretos - Unifeb. Especialização Lato Sensu em Didática do Ensino Superior, Av. Professor Roberto Frade Monte 389, Aeroporto, CEP 14283-078, Barretos-SP.

${ }^{2}$ Centro Universitário da Fundação Educacional de Barretos - Unifeb. Especialização Lato Sensu em Didática do Ensino Superior, Av. Professor Roberto Frade Monte 389, Aeroporto, CEP 14283-078, Barretos-SP.

\section{RESUMO}

A lei que autoriza o uso da fosfoetalonamina sintética por pacientes diagnosticados com neoplasia maligna, Lei Federal 13.269 de 13 de abril de 2016, é causa de pedir a Ação Direta de Inconstitucionalidade ADI/5.501-DF que tramita no Supremo Tribunal Federal - STF. A ação proposta pela Associação Médica Brasileira - AMB pediu e obteve em sede de medida cautelar a suspensão da aplicação da lei atacada. $\mathrm{O}$ argumento para a sanção da Lei era o de que o princípio da dignidade da pessoa humana tem força normativa irradiante para todo o ordenamento jurídico brasileiro, pois preserva o bem da vida como valor axiológico. A despeito do desconhecimento acerca da eficácia e dos efeitos colaterais desta substância, em seres humanos, a AMB questiona evidente incompatibilidade deste ato com os direitos constitucionais fundamentais sociais, o direito à saúde, previsto nos artigos $6^{\circ}$ e 196 da Constituição Federal/88, o direito à segurança e à vida, artigo $5^{\circ}$ - caput da $\mathrm{CF} / 88$, assim como o princípio da dignidade da pessoa humana, presente no artigo $1^{\circ}$, inciso III da CF/88. Conforme disposto nos artigos 10 a 12 da Lei 9.868/99 e no artigo 102, I, "p", da Constituição Federal, busca-se suspender imediatamente a eficácia e aplicabilidade do ato normativo com efeitos ex tunc e erga omnes, identificando a presença dos requisitos do "fumus boni iuris" e "periculum in mora". O trabalho em questão aborda aspectos jurídicos e éticos a respeito da supracitada lei à luz da melhor doutrina, discorrendo acerca das decisões acolhidas pela Suprema Corte.

Palavras-chave: Direto à saúde; Dignidade da Pessoa Humana; Fosfoetalonamina; Ética Médica.

\section{ABSTRACT}

The Federal Law 13.269 of April 13, 2016, authorizes the use of synthetic phosphoethanolamine by patients diagnosed with malignant neoplasm, and is the cause of request for the Direct Action of Unconstitutionality - ADI/5.501-DF processed in the Federal Supreme Court - STF. The action proposed by the Brazilian

\footnotetext{
Autor para correspondência: Cássia Cristina Lemes de Paula - Centro Universitário da Fundação Educacional de Barretos (Unifeb) - Av. Professor Roberto Frade Monte, 389 - Aeroporto - CEP: 14283-078 - Barretos (SP), Brasil -E-mail: cassialemes@terra.com.br
}

Recebido em: 03 de julho de 2017

Aceito para publicação em: 22 de Março 2018

https://doi.org/10.4322/1980-0029.052017 
Medical Association - AMB - requested and obtained, in a precautionary measure, the suspension of the application of the law under attack. The argument for the sanction of the Law was that the principle of the dignity of the human person has a normative force radiating to the entire Brazilian legal system, since it preserves the right to life as axiological value. Despite the lack of knowledge about the efficacy and side effects of this substance in humans, the AMB questions the apparent incompatibility of this act with fundamental social constitutional rights, the right to health, provided for in Articles 6 and 196 of the Federal Constitution/88; the right to security and life, in Article 5- caput of $\mathrm{CF} / 88$, as well as the principle of the dignity of the human person, in Article 1, item III of CF/88. Pursuant to articles 10 to 12 of Law 9.868/99, and in article 102, I, "p" of the Federal Constitution, the effectiveness and applicability of the regulatory act with ex tunc and erga omnes, identifying the presence of the "fumus boni iuris" and "periculum in mora". The work in question deals with legal and ethical aspects of the abovementioned law in the light of the best doctrine discussing decisions taken by the Supreme Court.

Keywords: Direct to health; Dignity of human person; Phosphoethanolamine; Medical Ethics.

\section{INTRODUÇÃO}

Com clara atuação e de importância inegável, o Poder Judiciário tem-se feito presente nas decisões políticas no Brasil nos últimos anos. Graças à Constituição Federal, a partir de 1988, o seu papel equilibra decisões de cunho legislativo e mesmo do Poder Executivo, quando deixam em aberto questões de grande relevância.

O exercício do direito à saúde, positivado em nosso ordenamento jurídico com a Constituição Federal de 1988, vem ganhando contornos nunca vistos, compelindo magistrados, promotores de justiça, procuradores públicos, advogados, entre outros operadores do direito, a lidarem com temas oriundos do Direito Sanitário e da política pública de saúde, nos três níveis de governo. E, também, compelindo gestores públicos de saúde a lidarem com a garantia efetiva deste direito social, em cada caso individual apresentado, através de uma determinação oriunda do Poder Judiciário que, muitas vezes, contrasta com a política estabelecida em matéria de assistência à saúde e com a própria lógica de funcionamento do sistema político (MARQUES, 2008).

O ativismo judicial é realidade inafastável da sociedade contemporânea, que decorre de uma crise de representatividade democrática instaurando a necessidade de intervenção do Poder Judiciário com o intuito de conter os abusos e as omissões dos Poderes Legislativos e Executivo, realizando a justiça social (MACHADO, 2011).

Nota-se presente, exercendo a guarda de direitos fundamentais, dentre eles os de segunda geração, invocando o mínimo existencial, sendo este o direito às condições mínimas de existência humana digna, que exige prestações de assistencialismo social. A questão da judicialização da saúde, por exemplo, é alvo de constantes debates doutrinários e jurisprudenciais.

É o caso da Lei 13.269/16 que sofreu Ação Direta de Inconstitucionalidade e agora está em processo de decisão dirigida à Corte Máxima, tendo como relator o Ministro Marco Aurélio, que dita sua posição diante do tema revestido de apelo social e emocional.

Tamanha complexidade referente ao tema remete à uma discussão que questiona os limites da judicialização e o ativismo judicial em relação à saúde. $\mathrm{O}$ trabalho em questão objetiva abordar aspectos jurídicos e éticos da lei 13.269 de 2016, ou seja, acompanhar o discorrer das decisões acolhidas pela Suprema Corte e suas súmulas.

\section{MATERIAIS E MÉTODOS}

Foi realizada pesquisa bibliográfica na área da Judicialização da saúde à luz dos princípios e garantias fundamentais junto à Ciência Jurídica.

Utilizou-se como base da pesquisa Ação Direta de Inconstitucionalidade 5.501 em nome da Associação Médica Brasileira - AMB como Petição Inicial, buscando a declaração de inconstitucionalidade da Lei n 13.269/2016, com o Relator Ministro Marco Aurélio. Além de pesquisa bibliográfica e doutrinária acerca do tema.

Ademais, utilizou-se o método dedutivo, especialmente a partir da interpretação legislativa brasileira atinente à Educação a Distância e dos conceitos doutrinários e teóricos aplicáveis.

\section{RESULTADOS E DISCUSSÃO}

Seguindo uma tendência mundial, a partir do século XX, um novo contexto se instalou e a intervenção do Estado Social através de prestações 
positivas tornou-se o principal meio de garantia dos direitos fundamentais. A introdução de direitos sociais nas constituições aliada à incessante busca de efetividade dos direitos fundamentais acelerou a consolidação do Estado Democrático de Direito e contribuiu, sensivelmente, para o surgimento do constitucionalismo contemporâneo (MACHADO, 2011).

A esta nova ideologia, pode-se incorporar a ideia de constitucionalismo fraternal, na qual o ser humano ocupa o centro do sistema jurídico e as atividades dos poderes devem ter em vista a garantia de sua dignidade. É neste contexto que se inserem as compreensões em torno do direito ao mínimo existencial (MACHADO, 2011).

Para Luis Roberto Barroso (2009a), no âmbito da dignidade da pessoa humana, inclui-se a proteção do mínimo existencial, “[...] locução que identifica o conjunto de bens e utilidades básicas para a subsistência física e indispensável ao desfrute dos direitos em geral".

$\mathrm{Na}$ busca de garantir direitos fundamentais e concretizar o Estado Constitucional e Democrático de Direito, se deu a proteção ao fenômeno da judicialização da política. A judicialização significa que questões de grande repercussão social estão sendo decididas pelo Poder Judiciário e não pelas instâncias políticas tradicionais (Congresso Nacional e Poder Executivo) (MACHADO, 2011).

Durante muito tempo, no Brasil, os tribunais autolimitaram-se, entendendo não poder adentrar o mérito de ato administrativo. Diversas manifestações do poder Judiciário, anteriores à Constituição de 1988, assumiram essa posição. No entanto, a Lei de Ação popular abriu ao judiciário brasileiro a apreciação do mérito do ato administrativo. Mas foi a Constituição de 1988 que trouxe os objetivos fundamentais da República Federativa do Brasil. É aí que o Estado Social de Direito se transforma em Estado Democrático de Direito (GRINOVER, 2011).

O grande conflito é que existem temas envolvendo aspectos técnicos ou científicos de grande complexidade, que podem não ter no juiz de direito o árbitro mais qualificado, por falta de informação ou conhecimento específico (BARROSO, 2009a).

Decisões judiciais podem causar problemas sociais maiores do que os que estão sendo tutelados, pois provoca redistribuição indireta de recursos de políticas púbicas e nem sempre garante o princípio da fraternidade (MACHADO, 2011).

O Poder Judiciário não tem como avaliar se determinado medicamento é efetivamente necessário para se promover a saúde e a vida. Mesmo que instruído por laudos técnicos, seu ponto de vista nunca seria capaz de rivalizar com o da Administração Pública. O juiz é um ator social que observa apenas os casos concretos, a microjustiça, ao invés da macrojustiça, cujo gerenciamento é mais afeto à Administração Pública (BARROSO, 2009a).

Segue o magistrado,

Exemplo emblemático nessa matéria tem sido o setor de saúde. Ao lado de intervenções necessárias e meritórias, tem havido uma profusão de decisões extravagantes ou emocionais em matéria de medicamentos e terapias, que põem em risco a própria continuidade das políticas públicas de saúde, desorganizando a atividade administrativa e comprometendo a alocação dos escassos recursos públicos (BARROSO, 2009a).

Nessa complexa ponderação é o direito à vida e à saúde de uns versus o direito à vida e à saúde de outros. Não há solução juridicamente fácil nem moralmente simples nessa questão, em que a dignidade da pessoa humana é o centro de irradiação dos direitos fundamentais (BARROSO, 2009c).

Assim, para que sejam fixadas balizas seguras e objetivas para solucionar esses casos de conflito de direitos fundamentais, é necessário analisar o princípio da proporcionalidade, que é o primeiro limite à concretização judicial do direito à saúde, em que, havendo colisão entre direitos fundamentais, pode-se limitar o raio de abrangência de um desses direitos, como critério de aferição da validade de limitações aos direitos fundamentais (GANDINI; BARIONE; SOUZA, 2008).

Outros dois princípios de suma importância nessa questão são o "mínimo existencial" $\times$ "reserva do possível". Não há dúvidas de que a assistência farmacêutica está compreendida no denominado "mínimo existencial". Opõe-se ao atendimento do "mínimo existencial" a insuficiência dos recursos financeiros do Estado para sua concretização. Essa insuficiência vem sendo aferida pela doutrina e pela jurisprudência, inclusive do Supremo Tribunal Federal, na esfera daquilo que se convencionou designar "reserva do possível” (GANDINI; BARIONE; SOUZA, 2008). 
A "reserva do possível", no que toca à possibilidade financeira do Estado, consubstancia a disponibilidade de recursos materiais para cumprimento de eventual condenação do Poder Público na prestação de assistência farmacêutica. Não obstante, da mesma forma em que não há dúvidas de que a assistência farmacêutica está compreendida no conceito de mínimo existencial, também não há qualquer dúvida de que o mais visível limite à atuação judicial é o postulado da reserva do possível. No entanto, é também o mais difícil de ser delimitado, sobretudo quando se trata da possibilidade financeira de cumprimento da ordem judicial (GANDINI; BARIONE; SOUZA, 2008).

Os problemas a serem decididos acerca dos medicamentos e da saúde pública no Brasil não se limitam aos custos financeiros, mas também ao que diz respeito à medicamentos não autorizados pela vigilância sanitária e quanto a sua eficácia não comprovada cientificamente. No que diz respeito particularmente à distribuição desses medicamentos, a competência de União, Estados e Municípios não está explicitada nem na Constituição nem na Lei.

A Lei, recentemente promulgada, 13.269/16 em seu Artigo $4^{\circ}$ determina

Ficam permitidos a produção, manufatura, importação, distribuição, prescrição, dispensação, posse ou uso da fosfoetalonamina sintética, direcionados aos usos de que trata esta lei, independentemente de registro sanitário, em caráter excepcional, enquanto estiverem em curso estudos clínicos acerca dessa substância (BARROSO, 2009b).

Um dos aspectos elementares a serem considerados pelo judiciário ao discutir a alteração das listas elaboradas pelo Poder Público envolve, por evidente, a comprovada eficácia das substâncias. Dessa forma, o Judiciário só pode determinar a inclusão, em lista, de medicamentos de eficácia comprovada, excluindo-se os experimentais e os alternativos. Outra diretriz evidente é que o Judiciário deverá considerar se o medicamento é indispensável para a manutenção da vida. Um medicamento vital à sobrevivência de determinados pacientes terá preferência sobre outro que apenas é capaz de proporcionar melhor qualidade de vida, sem, entretanto, ser essencial para a sobrevida (BARROSO, 2009c).

A Lei 13.269/16 recebe Ação Direta de Inconstitucionalidade pela Associação Médica Brasileira por desconhecimento amplo acerca da eficácia e dos efeitos colaterais desta substância, em seres humanos, desrespeitando atos normativos e direitos constitucionais fundamentais, quais sejam, direito à saúde, previsto no artigo $6^{\circ} \mathrm{e}$ 196 da Constituição Federal, direito à segurança e à vida (artigo $5^{\circ}$, caput da $\mathrm{CF}$ ), bem como o desrespeito ao princípio da dignidade da pessoa humana (Art. $1^{\circ}$, III da CF) (BRASIL, 2016a). Apesar de a substância somente ter passado por testes pré-clínicos, ou seja, em células e em camundongos, foi sancionada, entrando em total desacordo com a Lei 6.360/76 que, em seu artigo 16 , II, diz que o registro de drogas, medicamentos e insumos farmacêuticos deva acontecer através de comprovação científica e de análise, seja reconhecido como seguro e eficaz para o uso a que se propõe (BRASIL, 2016a).

Outro problema se encontra no artigo 12 da lei 6.360/76, lei que regula sobre a Vigilância Sanitária a que ficam submetidos os medicamentos. Este artigo expressa que nenhum dos produtos, a que se refere a Lei, inclusive os importados, poderia ser industrializado, exposto à venda ou entregue ao consumo antes de registrado no Ministério da Saúde.

Disserta assim o Senhor Ministro Relator Marco Aurélio (BRASIL, 2016c).

O direito à saúde não será plenamente concretizado sem que o Estado cumpra a obrigação de assegurar a qualidade das drogas distribuídas aos indivíduos mediante rigoroso crivo científico, apto a afastar desenganos, charlatanismos e efeitos prejudiciais ao ser humano. Na elaboração do ato impugnado, o Congresso Nacional, ao permitir a distribuição de remédio sem o controle prévio de viabilidade sanitária, não cumpriu com o dever constitucional de tutela da saúde da população. É no mínimo temerária - e potencialmente danosa - a liberação genérica do medicamento sem a realização dos estudos clínicos correspondentes, em razão da ausência, até o momento, de elementos técnicos assertivos da viabilidade da substância para o bem-estar do organismo humano. Salta aos olhos, portanto, a presença dos requisitos para o implemento da medida acauteladora.

Não se trata aqui de negar às pessoas diagnosticadas com câncer a esperança de cura de doença tão grave e devastadora. Em verdade, o que se busca é garantir que as expectativas de melhora com o uso de substâncias medicamentais sejam fundadas em evidências científicas e clínicas, sem expor os pacientes a maiores riscos de danos 
à saúde ou a tratamentos inócuos, que constituam somente ilusão (BRASIL, 2016b).

\section{CONCLUSÃO}

O tema presente envolve princípios e direitos fundamentais, como dignidade da pessoa humana, vida e saúde. Dessa forma, demostram consequências importantes, de modo que, como são cláusulas gerais, abrangem grandes possibilidades de sentidos, mesmo assim, podem entrar em rota de colisão entre si. Quando a Corte Superior precisa decidir sobre normas dessa natureza, deve-se ter como cenário principal as hipóteses de omissão dos Poderes Públicos, ou seja, o não atendimento do mínimo existencial. Dessa forma, havendo lei e atos administrativos, e não sendo devidamente cumpridos, devem os juízes e tribunais igualmente intervir.

\section{REFERÊNCIAS}

BARROSO, L. R. Curso de Direito Constitucional Contemporâneo. São Paulo: Saraiva, 2009a. 253 p.

BARROSO, L. R. Da falta de efetividade à constitucionalização excessiva: direito à saúde, fornecimento gratuito de medicamentos e parâmetros para a atuação judicial. In: BARROSO, L. R. Temas de direito constitucional. Rio de Janeiro: Renovar, 2009b. Tomo IV.

BARROSO, L. R. Judicialização, ativismo judicial e legitimidade democrática. Revista de Direito do Estado, v. 13, p. 71-91, 2009c.

BRASIL. Supremo Tribunal Federal. ADI $n$. $5.501 M C / D F$ : medida cautelar na ação direta de inconstitucionalidade: petição inicial da Associação Médica Brasileira - AMB, 15 de abril de 2016. Brasília, 2016a. Disponível em: $<$ http://docslide. com.br/documents/peticao-inicial-da-adi-5501. html>. Acesso em: 10 nov. 2016.
BRASIL. Supremo Tribunal Federal. ADI $n$. 5.501 $M C / D F$ : medida cautelar na ação direta de inconstitucionalidade: voto Ministro Luis Roberto Barroso, 19 de maio de 2016. Brasília, 2016b. Disponível em: <http://s.conjur.com.br/ dl/adi-5501-pilula-cancer-fosfoetalonamina.pdf $>$. Acesso em: 10 nov. 2016.

BRASIL. Supremo Tribunal Federal. ADI $n$. 5.501 MC/DF: medida cautelar na ação direta de inconstitucionalidade. Relator: Min. Marco Aurélio, 19 maio de 2016. Brasília: STF, 2016c. Disponível em: $<$ http://www.stf.jus.br/arquivo/ cms/noticiaNoticiaStf/anexo/adi5501MMA.pdf> Acesso em: 10 nov. 2016.

GANDINI, J. A. D.; BARIONE, S. F.; SOUZA, A. E. A Judicialização do Direito à Saúde: a obtenção de atendimento médico, medicamentos e insumos terapêuticos por via judicial: critérios e experiências. Brasília: BDJur, 2008. Disponível em: <http://ambito-juridico.com.br/site/index. php?artigo_id $=4182 \& n \_l i n k=$ revista_artigos leitura $>$. Acesso em: 10 nov. 2016.

GRINOVER, A. P. O controle de políticas públicas pelo Poder Judiciário. In: GRINOVER, A. P.; WATANABE, K. (Ed.). O controle jurisdicional de políticas públicas. 1. ed. Rio de Janeiro: Forense, 2011.

MACHADO, C. C. Limites ao ativismo judicial à luz do constitucionalismo fraterno. [s.1.]: Academus, 2011. Disponível em: $<$ http://www.academus.pro. br/mundojustica/artigomj_fraterno.pdf $>$. Acesso em: 10 nov. 2016.

MARQUES, S. B. Judicialização do direito à saúde. Revista de Direito Sanitário, v. 9, n. 2, p. 65-72, 2008. 